\title{
Sperm Motility as a Screening Strategy for the Identification of Microtubule Targeting Drugs
}

\author{
Aijaz Rashid \\ Postdoctoral Research Fellow, \\ National Institutes of Health, NIH, USA \\ clbaijaz@gmail.com
}

\section{ABSTRACT}

Microtubule targeting drugs are considered as successful anticancer agents. The hunt for novel microtubules targeting agents is an exciting anticancer research area, as new drugs, may not only show better potency and bioavailability but may also differentially affect the microtubule assembly and thus provide new insights about microtubule dynamics and polymer biology. Cold liable nature of microtubules is bases for tubulin isolation and screening of novel tubulin binding agents. Direct effect of different compounds on microtubule architecture and mitotic index in MCF-7/HeLa cell cultures is also used as a screening strategy. SRB/MTT assays that measure cell proliferation are also used as preliminary screening strategy to determine the effect of different compounds on cell proliferation for identifying microtubule targeting agents. Keeping in view the complexity of these assay systems, the possibility of sperm motility as a screening strategy for identifying the novel microtubule targeting drugs/agents was explored. So, the effect of known microtubule targeting agents on sperm motility was determined. The results suggest that nocodazole and colchicine does not affect sperm motility, thus impairment in sperm motility cannot be developed as a general method for screening of microtubule targeting drugs. However, curcumin was identified as a potent compound affecting sperm motility, indicating the possibility that in future curcumin or its derivatives might be used as natural contraceptives.

\section{INTRODUCTION \& DISCUSSION}

Microtubule targeting agents are considered as successful anticancer agents[1]. The hunt for novel microtubules targeting agents is an exciting research area as new microtubule targeting agents may not only show better potency and bioavailability but may also differentially affect the microtubule assembly and provide new insights about microtubule dynamics and polymer biology. Microtubules are cold liable tubulin polymers $[2,3]$. The cold sensitive characteristics of microtubules is exploited for tubulin isolation by allowing microtubules to depolymerise by keeping at $4^{0} \mathrm{C}$, followed by re-polymerization of Tubulin in the presence of $1 \mathrm{M}$ glutamate and $10 \% \mathrm{v} / \mathrm{v}$ DMSO at 37 ${ }^{0} \mathrm{C}$ [4-7]. Pure tubulin is further purified by passing through size exclusion gel filtration column. Similarly, MAP-rich tubulin is isolated by two consecutive cycles of polymerization and disassembly in the presence of $4 \mathrm{M}$ glycerol [5]. Both pure tubulin $(10 \mu \mathrm{M})$ and MAP-rich tubulin $(1 \mathrm{mg} / \mathrm{ml})$ in $25 \mathrm{mM}$ Pipes pH 6.8 containing $3 \mathrm{mM} \mathrm{MgCl} 2,1 \mathrm{mM}$ EGTA when incubated with or without different concentrations of compounds for X- min on ice allow binding of compounds to $\alpha \beta$-tubulin dimers $[6,7]$. Then, polymerization reaction is initiated by providing $1 \mathrm{mM}$ GTP and the course of polymerization can be monitored using spectrometer/turbidimeter at $37{ }^{\circ} \mathrm{C}[8]$. The assays determine the relative change in the polymerization kinetics of control and compound treated samples. The assay is useful in determining the polymerization/depolymerisation nature of tested compound with respect to vehicle treated control. It is to be noted that buffering conditions/ composition for compound screening varies from one lab. to another. Sulforhodamine B (SRB)assay and MTT assay determine the cell proliferation rate are also used as preliminary screening strategy to find out the effect of different compounds on cell proliferation[9-11]. Direct effect of different compounds on microtubule architecture and mitotic index in MCF-7 or HeLa cell is also used as a screening strategy. The affect on microtubule architecture and mitotic index is visualised and counted by performing staining for microtubules and phospho-histone h3 (ser10), respectively. Mitotic index is the number of cells in mitosis per 100 cells counted. As microtubule 
targeting agents hamper microtubule dynamics and tubulin polymerization, thus microtubule targeting agents inhibit cell cycle progression and cause mitotic block(increase mitotic index). The importance of novel microtubule targeting agents and complexity of sample preparation and protein purification process required for spectrometer/ turbidimeter assays, highlights the importance of exploring new screening strategies to identify microtubule targeting agents. The possibility of using sperm motility as a screening strategy for the identification of novel microtubule targeting drugs was explored. Experiment using three drugs was used as a pilot experiment to explore the validity of the project and boar semen was used as source of sperms and sperm motility was calculated by automatic semen analyser. Nocodazole, Curcumin and Colchicine are known microtubule targeting drugs[12-15]. The results of experiment suggest that Nocodazole and colchicine does not affect sperm motility(data not shown), thus sperm motility experiment cannot be developed as a general method for screening of microtubule targeting drugs.However, we have identified that Curcumin a microtubule targeting compound inhibits sperm motility while as Nocodazole and Colchicine, the potent microtubule targeting drugs have no effect on sperm motility. Thus, our results suggest that curcumin acts on sperm motility by other method rather than acting on flagellar microtubules of sperm[16]. The comparison of effects of these microtubule targeting drugs on somatic cell microtubule networks suggests that Nocodazole and Colchicines possess strong effects on microtubule network at lower concentrations than curcumin. Thus, these results suggests that flagellar microtubules are sheathed and protected from the access of microtubule targeting drugs and curcumin acts on sperm motility by some other mechanism, rather than acting on microtubules[17]. The results suggest that curcumin may act as potent natural contraceptive[18]. Following tables and plots show effect of curcumin on sperm motility and directional progressive motility of sperm population. Curcumin decreased sperm motility in a concentration dependent manner.

\section{Table 1: Control Sperm motility}

\begin{tabular}{|l|l|l|}
\hline Time Point (hours) & Motility of Control & $\begin{array}{l}\text { Progressive motility of } \\
\text { Control }\end{array}$ \\
\hline 0.17 (10minutes) & 84.7 & 11.26 \\
\hline 0.41 (25minutes) & 92.37 & 68.64 \\
\hline 0.57 (35minutes) & 63.4 & 34.02 \\
\hline 0.74 (45minutes) & 70.92 & 52.48 \\
\hline 0.91 (55minutes) & 89.44 & 78.05 \\
\hline 1.09 (65minutes) & 94.86 & 69.78 \\
\hline 1.21 (73 minutes) & 87.45 & 68.24 \\
\hline 1.34 (80minutes) & 86.89 & 68.56 \\
\hline $1.48(90$ minutes) & 56.86 & 34.56 \\
\hline
\end{tabular}

Table 2: $25 \mu M$ Curcumin Sperm motility

\begin{tabular}{|c|c|c|}
\hline Time Point (hours) & Motility of $25 \mu \mathrm{M}$ Curcumin & $\begin{array}{l}\text { Progressive motility } 25 \mu \mathrm{M} \\
\text { Curcumin }\end{array}$ \\
\hline 0.17 & 89.46 & 38.74 \\
\hline 0.41 & 71.17 & 47.86 \\
\hline 0.57 & 91.8 & 59.41 \\
\hline 0.74 & 89.74 & 78.13 \\
\hline 0.91 & 95.05 & 70.38 \\
\hline 1.09 & 91.32 & 75.09 \\
\hline 1.21 & 88.24 & 69.72 \\
\hline 1.34 & 58.26 & 44.56 \\
\hline 1.48 & 75.35 & 65.07 \\
\hline
\end{tabular}


Table 3: $75 \mu \mathrm{M}$ Curcumin Sperm motility

\begin{tabular}{|l|l|l|}
\hline Time Point (hours) & Motility of $\mathbf{7 5 \mu M}$ Curcumin & $\begin{array}{l}\text { Progressive motility } \\
\text { Curcumin }\end{array}$ \\
\hline 0.17 & 82.59 & 10.34 \\
\hline 0.41 & 44.36 & 21.81 \\
\hline 0.57 & 13.44 & 3.78 \\
\hline 0.74 & 34.48 & 17.24 \\
\hline 0.91 & 45.77 & 18.07 \\
\hline 1.09 & 21.24 & 8.03 \\
\hline 1.21 & 14.69 & 3.4 \\
\hline 1.34 & 16.38 & 8.72 \\
\hline 1.48 & 22.64 & 12.87 \\
\hline & & \\
\hline
\end{tabular}

Table 4: $125 \mu \mathrm{M}$ Curcumin Sperm motility

\begin{tabular}{|l|l|l|}
\hline Time Point (hours) & Motility of $\mathbf{1 2 5} \boldsymbol{\mu M}$ M Curcumin & $\begin{array}{l}\text { Progressive motility } \mathbf{1 2 5} \boldsymbol{M} \mathbf{M} \\
\text { Curcumin }\end{array}$ \\
\hline 0.17 & 90.75 & 32.08 \\
\hline 0.41 & 18.54 & 3.95 \\
\hline 0.57 & 16.75 & 6.23 \\
\hline 0.74 & 12.34 & 3.05 \\
\hline 0.91 & 17.78 & 3.36 \\
\hline 1.09 & 11.06 & 0.98 \\
\hline 1.21 & 12.17 & 2.89 \\
\hline 1.34 & 11.6 & 2.5 \\
\hline 1.48 & 9.65 & 1.54 \\
\hline
\end{tabular}

Table 5: $250 \mu \mathrm{M}$ Curcumin Sperm motility

\begin{tabular}{|l|l|l|}
\hline Time Point (hours) & $\begin{array}{l}\text { Motility of 250 } \mathrm{uM} \\
\text { Curcumin }\end{array}$ & $\begin{array}{l}\text { Progressive motility 250 } \boldsymbol{\mu M} \\
\text { Curcumin }\end{array}$ \\
\hline 0.17 & 49.36 & 7.84 \\
\hline & 7.1 & 1.27 \\
\hline 0.57 & 7.87 & 0.93 \\
\hline 0.74 & 7.67 & 0.47 \\
\hline 0.91 & 8.6 & 2.74 \\
\hline 1.09 & 0 & 0 \\
\hline 1.21 & 0 & 0 \\
\hline 1.34 & 0 & 0 \\
\hline 1.48 & 0 & 0 \\
\hline
\end{tabular}


Table 6: $500 \mu M$ Curcumin Sperm motility

\begin{tabular}{|c|c|c|}
\hline Time Point (hours) & Motility of $500 \mu \mathrm{M}$ Curcumin & $\begin{array}{l}\text { Progressive motility } 500 \mu \mathrm{M} \\
\text { Curcumin }\end{array}$ \\
\hline 0.17 & 5.97 & 1.26 \\
\hline 0.41 & 0 & 0 \\
\hline 0.57 & 0 & 0 \\
\hline 0.74 & 0 & 0 \\
\hline 0.91 & 0 & 0 \\
\hline 1.09 & 0 & 0 \\
\hline 1.21 & 0 & 0 \\
\hline 1.34 & 0 & 0 \\
\hline 1.48 & 0 & 0 \\
\hline
\end{tabular}

Table 7: $1000 \mu \mathrm{M}$ Curcumin Sperm motility

\begin{tabular}{|l|l|l|}
\hline Time Point (hours) & Motility of 1mM Curcumin & $\begin{array}{l}\text { Progressive motility } \mathbf{1} \boldsymbol{M} \mathbf{M} \\
\text { Curcumin }\end{array}$ \\
\hline 0.17 & 7.3 & 1.31 \\
\hline 0.41 & 0 & 0 \\
\hline 0.57 & 0 & 0 \\
\hline 0.74 & 0 & 0 \\
\hline 0.91 & 0 & 0 \\
\hline 1.09 & 0 & 0 \\
\hline 1.21 & 0 & 0 \\
\hline 1.34 & 0 & 0 \\
\hline 1.48 & 0 & 0 \\
\hline
\end{tabular}

Graphical representation showing effect of different concentrations of Curcumin on Sperm motility:

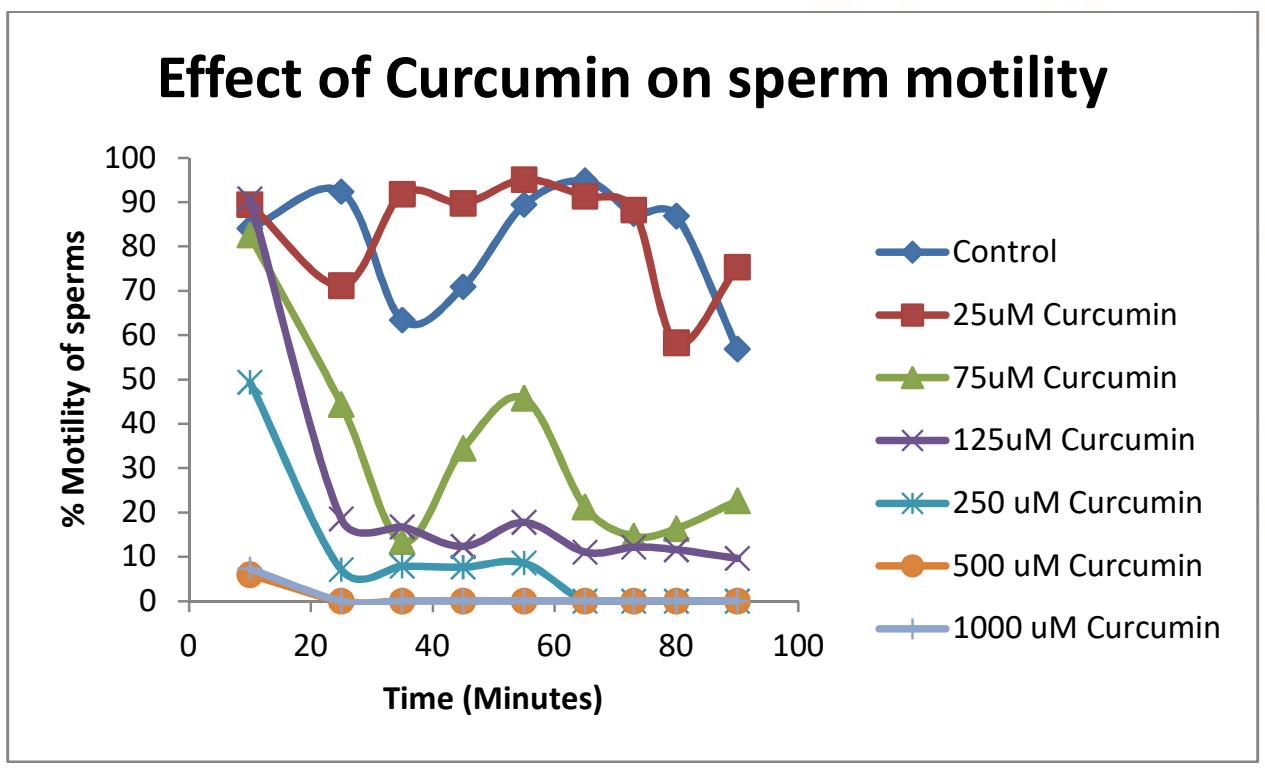

The traces depict the effect of curcumin on sperm shows concentration dependent decrease in presence motility at different time points. The sperm motility of curcumin. 


\section{RESULTS AND CONCLUSION:}

Sperm motility assay cannot be used a general screening test for identifying microtubule targeting agents. Curcumin a mild microtubule targeting agent affect sperm motility in a concentration dependent manner. The results suggest possible future use of curcumin as a contraceptive.

\section{REFERENCES:}

1) Jordan, M.A. and L. Wilson, Microtubules as a target for anticancer drugs. Nat Rev Cancer, 2004. 4(4): p. 253-65.

2) Ochoa, C.D., T. Stevens, and R. Balczon, Cold exposure reveals two populations of microtubules in pulmonary endothelia. Am J Physiol Lung Cell Mol Physiol, 2011. 300(1): p. L132-8.

3) Rashid, A., et al., Thalidomide (5HPP-33) suppresses microtubule dynamics and depolymerizes the microtubule network by binding at the vinblastine binding site on tubulin. Biochemistry, 2015. 54(12): p. 2149-59.

4) Hamel, E. and C.M. Lin, Glutamate-induced polymerization of tubulin: characteristics of the reaction and application to the large-scale purification of tubulin. Arch Biochem Biophys, 1981. 209(1): p. 29-40.

5) Chatterji, B.P., et al., HMBA depolymerizes microtubules, activates mitotic checkpoints and induces mitotic block in MCF-7 cells by binding at the colchicine site in tubulin. Biochem Pharmacol. 2010 Jul 1;80(1):50-61. doi: 10.1016/j.bcp.2010.03.016. Epub 2010 Mar 17., 2010.

6) Inatsuki, S., et al., Tubulin-polymerization inhibitors derived from thalidomide. Bioorg Med Chem Lett, 2005. 15(2): p. 321-5.

7) Yanagawa, T., et al., Tubulin polymerization inhibitors with a fluorinated phthalimide skeleton derived from thalidomide. Bioorg Med Chem Lett, 2006. 16(18): p. 4748-51.

8) Mirigian, M., et al., Measurement of in vitro microtubule polymerization by turbidity and fluorescence. Methods Cell Biol, 2013. 115: p. 215-29.

9) Vichai, V. and K. Kirtikara, Sulforhodamine $B$ colorimetric assay for cytotoxicity screening. Nat Protoc, 2006. 1(3): p. 1112-6.

10) Orellana, E.A. and A.L. Kasinski, Sulforhodamine $B(S R B)$ Assay in Cell Culture to Investigate Cell Proliferation. Bio Protoc, 2016. 6(21).
11) Sliwka, L., et al., The Comparison of MTT and CVS Assays for the Assessment of Anticancer Agent Interactions. PLoS One, 2016. 11(5): p. e0155772.

12) Vasquez, R.J., et al., Nanomolar concentrations of nocodazole alter microtubule dynamic instability in vivo and in vitro. Mol Biol Cell, 1997. 8(6): p. 973-85.

13) Banerjee, M., P. Singh, and D. Panda, Curcumin suppresses the dynamic instability of microtubules, activates the mitotic checkpoint and induces apoptosis in MCF-7 cells. FEBS J, 2010. 277(16): p. 3437-48.

14) Vandecandelaere, A., S.R. Martin, and Y. Engelborghs, Response of microtubules to the addition of colchicine and tubulin-colchicine: evaluation of models for the interaction of drugs with microtubules. Biochem J, 1997. 323 ( Pt 1): p. 189-96.

15) Gireesh, K.K., et al., CIL-102 binds to tubulin at colchicine binding site and triggers apoptosis in MCF-7 cells by inducing monopolar and multinucleated cells. Biochem Pharmacol, 2012. 84(5): p. 633-45.

16) Naz, R.K., The Effect of Curcumin on Intracellular $\quad \mathrm{HH}(\mathrm{pHi}), \quad$ Membrane Hyperpolarization and Sperm Motility. J Reprod Infertil, 2014. 15(2): p. 62-70.

17) Inaba, K., Sperm flagella: comparative and phylogenetic perspectives of protein components. Mol Hum Reprod, 2011. 17(8): p. 524-38.

18) Naz, R.K., Can curcumin provide an ideal contraceptive? Mol Reprod Dev, 2011. 78(2): p. 116-23. 